\title{
Testing Weak-Form Market Efficiency On The TSX
}

Ilona Shiller, University of New Brunswick, Canada

Ishmael Radikoko, University of Botswana, Canada

\begin{abstract}
This study tests the validity of the weak-form EMH on the Canadian TSX equity market using seven TSX daily index returns. Quantitatively, a variety of statistical tests is used to test for the randomness of return series. Results of the common statistical (i.e., the autocorrelation, the BG, the runs) tests all suggest that returns are serially correlated, except returns on the TSX 60 capped index. After rejecting the RWM of TSX indices using univariate unit root (i.e., ADF, PP, KPSS), we proceed to test for the possibility of nonlinear dynamic patterns present in return series. BDS results reject an IID underlying residual series after fitting AR(2) to TSX daily index returns, indicating that a deterministic chaotic process describes the data well. This finding of a temporal dependency is supported also by results of the R/S analysis, which indicates that all TSX index returns possess long-memory properties of an anti-persistent trend-reversing behaviour with two indices showing stronger degree of anti-correlation and five indices showing weaker degree of anti-correlation. Overall, results uniformly reject the RWM governing TSX equity index returns, implying that the Canadian equity market is weak-form inefficient.
\end{abstract}

Keywords: Information and Market Efficiency; Weak-Form Efficiency Tests; RWM; Equity Returns

\section{INTRODUCTION}

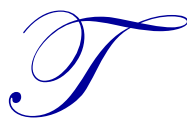

his study tests the efficiency of the Toronto Stock Exchange (TSX) using Canadian Stock Index returns ${ }^{1}$ and compares results to the results of representative studies testing the efficiency of other developed exchanges like the NYSE, London Stock Exchange (LSE), Tokyo Stock Exchange (TSE), and the NASDAQ stock exchange. The degree of efficiency on TSX is important for accounting and economic research on production/investment decisions, adherence to regulatory standards, performance evaluation benchmarking, and corporate disclosure decision-making.

The research on market efficiency has been carried out in different countries and using different techniques. The empirical results are controversial; some support the EMH, whereas others do not. Most developed markets are found to be weak-form efficient. Developing markets, on the contrary, are found to be weak-form inefficient: there is evidence of a serial autocorrelation and of a substantial dependence in successive security price changes. The latter implies that developing countries do not follow the RWM.

The contribution of this study is to test for the randomness of return series using a variety of statistical tests. We uniformly reject the RWM and find that TSX Index returns are anti-persistent.

Qualitatively, the efficiency on the TSX is compared against the efficiency on other representative exchanges around the world (the NYSE, the NASDAQ, the LSE, and the TSE) in terms of their information disclosure, liquidity, transparency, data management and distribution practices, clearing and settlement procedures, and regulation. The TSX is one of the few exchanges currently operating in Canada. Other Canadian exchanges include the TSX Venture exchange and the Toronto Montreal exchange. Since its formation, the TSX went through many changes such as changes in premises' utilisation, trading systems, management and modification of rules, etc.

\footnotetext{
${ }^{1}$ See appendix 1 for details.
} 
Table 1.1 compares world stock exchanges' based on indicators related to market value, number of listed companies, and turnover value (liquidity) reported on July of 2008. The implications of the presented in the table indicators for TSX are as follows. First, the TSX is the seventh of the top 10 largest stock exchanges in the world by dollar volume. It is the largest in Canada and the third largest in North America after the NYSE and the NASDAQ. Second, the total market capitalization on the TSX is half that on TSE with 3,951 listed issuers reported on July 2008. Third, statistics in Table 1.2 reveal that, as of December 2007, the TSX: (i) had 1,613 listed companies with a total market capitalisation of $\$ 2,093.5$ billion; (ii) brokers/dealers transacted 118,578,200 times and traded 96,109 million with a market value of $\$ 1,697.2$ billion by 2007 year-end; and (iii) TSX ranked 14th in the world by total share turnover (US\$1.36 trillion). We summarize trading, clearing and settlement, data management and distribution, and regulatory practices at largest world exchange in Table 1.3.

Table 1.1: World Stock Exchanges' Comparison in Terms of Market Value, Number of Listed Companies and Turnover Value (Liquidity) as of July $\mathbf{2 0 0 8}^{2}$

\begin{tabular}{|l|c|c|c|c|}
\hline \multicolumn{1}{|c|}{ Region } & Stock Exchange & $\begin{array}{c}\text { Market Value (Trillion in } \\
\text { of \$US) }\end{array}$ & $\begin{array}{c}\text { Number of } \\
\text { Listed } \\
\text { Companies }\end{array}$ & $\begin{array}{c}\text { Turnover } \\
\text { Value } \\
\text { (\$Trillion) }\end{array}$ \\
\hline Americas/Europe & NYSE Euronext & $\$ 20.7$ & 2299 & 28.7 \\
\hline Asia-Pacific & Tokyo Stock exchange & 4.63 & 2414 & 5.45 \\
\hline Americas & NASDAQ & 4.39 & 3069 & 12.4 \\
\hline Europe & London Stock Exchange & 4.21 & 3307 & 9.14 \\
\hline Asia-Pacific & Shangai Stock Exchange & 3.02 & - & - \\
\hline Asia-Pacific & Hong Kong Stock Exchange & 2.97 & $\mathbf{3 9 5 1}$ & - \\
\hline Americas & Toronto Stock Exchange & $\mathbf{2 . 2 9}$ & - & - \\
\hline Europe & Frank Furt Stock Exchange & 2.12 & - & - \\
\hline Europe & Madrid Stock Exchange & 1.83 & 4887 & - \\
\hline South Asia & Bombay Stock Exchange & 1.61 & & \\
\hline
\end{tabular}

Table 1.2: Summary of 2007 TSX Data on Trading, Listings and Financing ${ }^{3}$

\begin{tabular}{|l|c|}
\hline \multicolumn{1}{|c|}{ Toronto Stock Exchange Particulars } & Values \\
\hline Listed Issuers & 1,613 \\
\hline Total Listed Issuer Market Capitalization & $\$ 2.093 .5$ billion \\
\hline Volume Traded in 2007 (number of shares) & 96.1 billion \\
\hline Value Traded in 2007 & $\$ 1,697.2$ billion \\
\hline Financings in 2007 & $\$ 47.6$ billion \\
\hline New Listings in 2007 & 207 \\
\hline
\end{tabular}

Table 1.3: Comparison of Trading, Clearing \& Settlement, Data Management and Distribution, and Regulatory Practices at Largest World Exchanges

\begin{tabular}{|c|c|c|c|c|c|}
\hline Exchange & TSX & NASDAQ & NYSE & LSE & TSE \\
\hline Trading & TSX Quantum & $\begin{array}{l}\text { Electronic } \\
\text { Communication } \\
\text { Networks (ECNs) }\end{array}$ & $\begin{array}{l}\text { NYSE Euronext } \\
\text { Advanced } \\
\text { Trading Solutions } \\
\text { (via SFTI) }\end{array}$ & $\begin{array}{l}\text { TradElect } \\
\text { (June 2007) }\end{array}$ & $\begin{array}{l}\text { Computer Assisted } \\
\text { order routing \& } \\
\text { Execution System } \\
(\text { CORES) }\end{array}$ \\
\hline $\begin{array}{l}\text { Central Limit } \\
\text { Order Book }\end{array}$ & TSX Infinity & - & 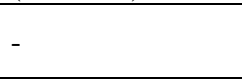 & $\begin{array}{l}\text { SETS } \\
(\text { Feb 2001) }\end{array}$ & (2x \\
\hline Clearing & \multirow{2}{*}{ CDS Limited } & $\begin{array}{l}\text { National Securities } \\
\text { Clearing } \\
\text { Corporation } \\
\text { (NSCC) \& DTC }\end{array}$ & \multirow{2}{*}{$\begin{array}{l}\text { Depository Trust } \\
\text { Company (DTC) } \\
\text { \& Clearing } \\
\text { Organisation ( } \\
\text { DTCC) }\end{array}$} & $\begin{array}{l}\text { London } \\
\text { Clearing } \\
\text { House }\end{array}$ & $\begin{array}{l}\text { Japan Securities } \\
\text { Clearing Corporation } \\
\text { (JSCC) }\end{array}$ \\
\hline Settlement & & $\begin{array}{l}\text { Depository Trust } \\
\text { Company (DTC) }\end{array}$ & & $\begin{array}{l}\text { Euroclear UK } \\
\text { and Ireland }\end{array}$ & $\begin{array}{l}\text { Japan Securities } \\
\text { Depositary Center } \\
\text { (JASDEC) \& Bank } \\
\text { of Japan }\end{array}$ \\
\hline
\end{tabular}

\footnotetext{
${ }^{2}$ Source: World Federation of Exchanges (http://www.world-exchanges.org).

${ }^{3}$ TSX website (www.tsx.com).
} 
Table 1.3 cont.

\begin{tabular}{|c|c|c|c|c|c|}
\hline $\begin{array}{l}\text { Data } \\
\text { Management and } \\
\text { Distribution }\end{array}$ & TSX Datalinx & $\begin{array}{l}\text { Small order } \\
\text { execution system } \\
\text { and Select Net }\end{array}$ & Wombat & $\begin{array}{l}\text { Proquote; } \\
\text { online price } \\
\text { vendors }\end{array}$ & $\begin{array}{l}\text { Authorized vendors } \\
\text { or specialists; Mains } \\
\text { Mail }\end{array}$ \\
\hline \multicolumn{6}{|l|}{ Regulation } \\
\hline $\begin{array}{l}\text { National } \\
\text { Regulatory } \\
\text { Organizations }\end{array}$ & $\begin{array}{l}\text { Investment } \\
\text { Industry } \\
\text { Regulation of } \\
\text { Canada }\end{array}$ & $\begin{array}{l}\text { Security Exchange } \\
\text { Commision (SEC) }\end{array}$ & $\begin{array}{l}\text { Security } \\
\text { Exchange } \\
\text { Commision } \\
\text { (SEC) }\end{array}$ & $\begin{array}{l}\text { Securities and } \\
\text { Investment } \\
\text { Board }\end{array}$ & $\begin{array}{l}\text {-Financial Services } \\
\text { Agency (FSA) } \\
\text {-Securities \& } \\
\text { Exchange } \\
\text { Surveilance } \\
\text { Commision (SESC) }\end{array}$ \\
\hline $\begin{array}{l}\text { Exchange's } \\
\text { Regulation }\end{array}$ & $\begin{array}{l}\text { Market Regulation } \\
\text { Services Inc. (RS) }\end{array}$ & - & $\begin{array}{l}\text { NYSE Regulation } \\
\text { Incorporated }\end{array}$ & $\begin{array}{l}\text { Financial } \\
\text { Services } \\
\text { Authority }\end{array}$ & FSA \\
\hline
\end{tabular}

Aitken and Siow (2003), using intra-day trade and quote data for 7 years downloaded from the Reuters database, rate world equity markets in terms of market efficiency and integrity. First, they attach separate efficiency/integrity ratings to each examined market. Then, overall ratings are calculated by adding respective market efficiency/integrity ratings together. They attach the following overall ratings to the four exchanges discussed above: the NYSE (ranked \# 1), the TSX (ranked \# 4), the TSE (ranked \#5), and the LSE (ranked \#7).

What does past research conclude regarding the weak-form efficiency of the Canadian equity market? Porteba and Summers (1988) investigate transitory components in stock returns of Canadian, ${ }^{4}$ US companies, and companies of 17 other countries. Specifically, they test for mean-reversion after showing that common statistical tests (the variance ratio test and ARMA models) have little power to detect any persistent deviations of returns from their fundamental values. Results show that stock returns exhibit positive (negative) serial correlations over shorter (longer) intervals of time. Furthermore, even though the RWM cannot be rejected at high significance levels on the basis of individual datasets used in isolation, the results on the basis of all data together allows one to strengthen the case against the overall validity of the RWM. Subsequent studies on the weak-form efficiency of Canadian stock markets find that the results are data-specific. For example, Freund et al (1997) use the Rescaled Range Analysis $(\mathrm{R} / \mathrm{S})$ to examine the TSX efficiency, before and after the introduction of electronic trading. Using daily (monthly stock index) data for selected individual stocks, they reject (fail to reject) the RWM. They attribute the difference in daily and monthly results to the effect of aggregation and indexation of return data. In addition, they compare the performance of several simple 'technical' trading strategies to that of a 'buy and hold' strategy using daily data for 25 stocks. They find that, despite the presence of non-random patterns in return data, technical trading rules fail to exploit profitable information to outperform the buy and hold strategy. This implies that the rejection of the RWM does not necessarily translate into an abnormal performance. Freund and Pagano (2000) reach a similar conclusion after testing (using non-parametric tests) for market efficiency on the TSX and the NYSE, before and after the introduction of electronic trading. They show that electronic trading has no impact on the efficiency of both markets, and for TSX, it actually coincides with an improvement in efficiency. Chan et al. (1997) study international stock market efficiency and the integration of eighteen markets including Canada. Their Phillips-Perron (PP) test results show that all monthly stock indices of eighteen national equity markets have a unit root, suggesting that those stock markets are efficient individually.

The layout of this study is as follows. The next section describes the data and methodology used. It also discusses the results. The last section contains concluding remarks.

\section{DATA, METHODOLOGY, AND FINDINGS}

\section{Data Description and Its Properties}

The data used in this research includes seven daily Canadian index price series, downloaded from the Bloomberg database. The sample extends up to March 20, 2008 and comprises end-of-day prices. S\&P/TSX

${ }^{4}$ Canadian returns on TSX-listed stocks cover the period from 1919 to 1985. 
Composite Index covers a period of twenty-eight years, from January 2, 1980 to March 20, 2008, for a total of 7,105 end-of-day observations. S\&P/TSX 60 Index series begins from January 29, 1982; S\&P/TSX 60 Capped Index from November 20, 2000; S\&P/TSX Small Cap Index - from May 17, 1999; S\&P/TSX Venture Index - from December 7, 2001; S\&P/TSX Composite Capped Index - from December 29, 1989; S\&P/TSX Completion Index from May 17, 1999. S\&P/TSX 60 Capped Index series includes 1,846 observations; S\&P/TSX Small Cap Index 2,227 observations; S\&P/TSX Venture Index - 1,582 observations; S\&P/TSX Composite Capped Index - 4,586 observations; and S\&P/TSX Completion Index - 2,227 observations. ${ }^{5}$

Daily index price series are converted into continuously compounded returns. Logarithmic returns are used because they are analytically more tractable and are more likely to be normally distributed. Freund et al. (1997) also argues that logarithmic transformation removes most of linear dependence between today's returns and past daily returns.

Table 2.1 summarizes descriptive statistics of daily return series for all seven indices (i.e., means, maximums, minimums, standard deviations, skewness, kurtosis, Jarque-Bera statistics and their associated $p$-values).

Table 2.1: Descriptive Statistics of the Daily Continuously Compounded Canadian Equity Returns

\begin{tabular}{|c|c|c|c|c|c|c|c|c|c|c|c|}
\hline Index & Start & End & Observations & Mean & Maximum & Minimum & $\begin{array}{l}\text { Std. } \\
\text { Dev. }\end{array}$ & Skewness & Kurtosis & $\begin{array}{c}\text { Jarque- } \\
\text { Bera }\end{array}$ & \begin{tabular}{|c|}
$J B$ \\
$p$-value
\end{tabular} \\
\hline $\begin{array}{l}\text { SPTSX } \\
\text { INDEX }\end{array}$ & 02-Jan-80 & 20-Mar-08 & 7104 & 0.00028 & 0.08646 & -0.11795 & 0.00881 & -0.91561 & 15.45925 & 46941.564 & 0.00 \\
\hline $\begin{array}{l}\text { SPTSX60 } \\
\text { INDEX }\end{array}$ & 29-Jan-82 & 21-Mar-08 & 6580 & 0.00031 & 0.07994 & -0.12232 & 0.00962 & -0.82601 & 14.37616 & 36230.057 & 0.00 \\
\hline $\begin{array}{l}\text { SPTSX60C } \\
\text { INDEX }\end{array}$ & 20-Nov-00 & 22-Mar-08 & 1845 & 0.00027 & 0.04512 & -0.04769 & 0.00945 & -0.26807 & 4.7846 & 266.92679 & 0.00 \\
\hline $\begin{array}{l}\text { SPTSXS } \\
\text { INDEX }\end{array}$ & 17-May-99 & 23-Mar-08 & 2226 & 0.00021 & 0.03751 & -0.06375 & 0.00887 & -0.83338 & 6.96465 & 1715.5544 & 0.00 \\
\hline $\begin{array}{l}\text { SPTSXVEN } \\
\text { INDEX }\end{array}$ & 07-Dec-01 & 24-Mar-08 & 1581 & 0.00057 & 0.05466 & -0.09098 & 0.0112 & -1.41615 & 11.41054 & 5188.2599 & 0.00 \\
\hline $\begin{array}{l}\text { SPTSXC } \\
\text { INDEX }\end{array}$ & 29-Dec-89 & 25-Mar-08 & 4585 & 0.00029 & 0.04684 & -0.06373 & 0.00819 & -0.55969 & 7.3526 & 3858.6912 & 0.00 \\
\hline $\begin{array}{l}\text { SPTSXM } \\
\text { INDEX }\end{array}$ & 17-May-99 & 26-Mar-08 & 2226 & 0.00031 & 0.05259 & -0.06413 & 0.01009 & -0.34769 & 6.71186 & 1322.7478 & 0.00 \\
\hline
\end{tabular}

Results in Table 2.1 show that the distribution of return series does not follow a normal curve. ${ }^{6}$ Reported skewness statistics of all index return series are not zero, with statistics high and negative for the TSX Composite Index (0.92), the TSX 60 Index (0.83), and the TSX Small Cap Index (0.83). Reported kurtosis statistics of all index return series are greater than three, meaning that their underlying distribution is leptokurtic. Specifically, high kurtosis values are reported for the TSX Composite Index, the TSX Small Cap Index, and the TSX Venture Index, which are 15.5, 14.4, and 11.4 respectively. This means that the distribution of Canadian Index returns is not normal, violating the prior condition of a random walk model. Reported Jarque-Bera (JB) statistics (which test for normality) and their corresponding $p$-values confirm our initial conclusion of a non-normal return distribution (the lowest JB value is 266.92 for the TSX 60 Capped Index and the highest is 46,941.56 for the TSX Composite Index).

\section{Empirical Results}

We use both, parametric (i.e., autocorrelation (AC) and Breusch-Godfrey (BG)) and non-parametric (i.e., Brock, Dechert, and Sheinkman (BDS) and runs tests), tests to test weak-form efficiency of the Canadian stock market. We also use univariate unit root tests including Augmented Dickey-Fuller (ADF), Phillips-Perron (PP), and Kwiatkowski, Phillips, Schmidt, and Shin (KPSS) tests.

To examine the serial dependence in return series, we use the runs test and the serial correlation coefficient (i.e., autocorrelation and Breusch-Godfrey) tests. Autocorrelation is a parametric test which is widely used in empirical research and it tests the relationship between current and previous period stock returns.

\footnotetext{
${ }^{5}$ See Appendix 1 for the description of each index.

${ }^{6}$ A perfectly normal distribution is the one with a skewness value of zero and a kurtosis of approximately 3 in a Gaussian distribution. Kendal (1943) show that a normal kurtosis is equal to 2.902 using the model, $3(n-1 / n+1)$ that he developed. Where $n=$ sample size.
} 
Table 2.2 presents autocorrelation coefficients and their associated Q-Statistics up to 12 lags. The Qstatistic test the joint hypothesis that all the individual autocorrelation coefficients are simulteneously equal to zero. Since the sample size is large for all the indices studied, Q-statistic is approximately distributed as the chi-square distribution with 12 degrees of freedom. The results reject the null hypothesis of no serial autocorrelation for all indices at $1 \%$ significance level, except for the TSX 60 capped index, ${ }^{7}$ providing an initial evidence of an overall weak-form Canadian equity market inefficiency. All other index autocorrelation coefficients are statistically different from zero at all examined lags, based on reported zero or close to zero Q-statistic probabilities.

Table 2.2: Auto-Correlation Test (Logarithms of Daily Market Returns)

\begin{tabular}{|c|c|c|c|c|c|c|c|c|c|c|c|c|c|}
\hline \multicolumn{14}{|c|}{$\begin{array}{l}\text { This table reports the results of the autocorrelation test and th } \\
\text { correlation coefficients at diffrent lags are zero. The Q-statis } \\
\text { The test statistics is asymptotically chi-square distributed. }\end{array}$} \\
\hline Index & Lag / df & 1 & 2 & 3 & 4 & 5 & 6 & 7 & 8 & 9 & 10 & 11 & 12 \\
\hline \multirow{3}{*}{$\begin{array}{l}\text { SPTSX } \\
\text { INDEX }\end{array}$} & Coefficient & 0.135 & 0.004 & 0.007 & -0.012 & 0.022 & 0.006 & -0.011 & 0.010 & -0.017 & 0.009 & 0.011 & 0.036 \\
\hline & Q-Statistic & 130.360 & 130.456 & 130.836 & 131.911 & 135.229 & 135.454 & 136.330 & 137.098 & 139.051 & 139.590 & 140.500 & 149.726 \\
\hline & Probability & 0.00 & 0.00 & 0.00 & 0.00 & 0.00 & 0.00 & 0.00 & 0.00 & 0.00 & 0.00 & 0.00 & 0.00 \\
\hline \multirow{3}{*}{$\begin{array}{c}\text { SPTSX60 } \\
\text { INDEX }\end{array}$} & Coefficient & 0.086 & -0.006 & 0.004 & -0.023 & 0.009 & -0.005 & -0.029 & -0.002 & -0.013 & 0.017 & 0.007 & 0.035 \\
\hline & Q-Statistic & 48.388 & 48.590 & 48.715 & 52.293 & 52.819 & 52.990 & 58.581 & 58.599 & 59.752 & 61.735 & 62.035 & 69.971 \\
\hline & Probability & 0.00 & 0.00 & 0.00 & 0.00 & 0.00 & 0.00 & 0.00 & 0.00 & 0.00 & 0.00 & 0.00 & 0.00 \\
\hline \multirow{3}{*}{$\begin{array}{c}\text { SPTSX60C } \\
\text { INDEX }\end{array}$} & Coefficient & -0.046 & 0.010 & -0.008 & -0.017 & 0.000 & 0.008 & -0.046 & 0.013 & -0.005 & 0.004 & -0.007 & -0.012 \\
\hline & Q-Statistic & 3.953 & 4.154 & 4.271 & 4.800 & 4.800 & 4.906 & 8.911 & 9.241 & 9.293 & 9.319 & 9.418 & 9.706 \\
\hline & Probability & 0.05 & 0.13 & 0.23 & 0.31 & 0.44 & 0.56 & 0.26 & 0.32 & 0.41 & 0.50 & 0.58 & 0.64 \\
\hline \multirow{3}{*}{$\begin{array}{l}\text { SPTSXS } \\
\text { INDEX }\end{array}$} & Coefficient & 0.168 & 0.033 & -0.007 & -0.007 & -0.043 & -0.050 & -0.011 & 0.009 & 0.008 & 0.036 & 0.079 & -0.003 \\
\hline & Q-Statistic & 62.550 & 64.967 & 65.070 & 65.175 & 69.268 & 74.930 & 75.214 & 75.409 & 75.543 & 78.434 & 92.412 & 92.436 \\
\hline & Probability & 0.00 & 0.00 & 0.00 & 0.00 & 0.00 & 0.00 & 0.00 & 0.00 & 0.00 & 0.00 & 0.00 & 0.00 \\
\hline \multirow{3}{*}{$\begin{array}{l}\text { SPTSXVE } \\
\text { N INDEX }\end{array}$} & Coefficient & 0.187 & 0.071 & 0.028 & 0.083 & 0.068 & -0.004 & -0.019 & 0.009 & 0.036 & 0.092 & 0.006 & -0.040 \\
\hline & Q-Statistic & 55.100 & 63.103 & 64.312 & 75.338 & 82.749 & 82.771 & 83.367 & 83.498 & 85.566 & 98.923 & 98.978 & 101.582 \\
\hline & Probability & 0.00 & 0.00 & 0.00 & 0.00 & 0.00 & 0.00 & 0.00 & 0.00 & 0.00 & 0.00 & 0.00 & 0.00 \\
\hline \multirow{3}{*}{$\begin{array}{l}\text { SPTSXC } \\
\text { INDEX }\end{array}$} & Coefficient & 0.094 & 0.015 & 0.015 & -0.027 & -0.002 & -0.001 & -0.051 & 0.008 & 0.000 & 0.019 & 0.012 & 0.045 \\
\hline & Q-Statistic & 40.930 & 41.959 & 42.994 & 46.401 & 46.417 & 46.420 & 58.431 & 58.741 & 58.741 & 60.378 & 61.024 & 70.311 \\
\hline & Probability & 0.00 & 0.00 & 0.00 & 0.00 & 0.00 & 0.00 & 0.00 & 0.00 & 0.00 & 0.00 & 0.00 & 0.00 \\
\hline \multirow{3}{*}{$\begin{array}{c}\text { SPTSXM } \\
\text { INDEX }\end{array}$} & Coefficient & 0.131 & 0.006 & -0.040 & -0.022 & -0.007 & -0.059 & -0.016 & 0.030 & 0.007 & 0.009 & 0.068 & 0.052 \\
\hline & Q-Statistic & 38.010 & 38.086 & 41.645 & 42.716 & 42.828 & 50.505 & 51.081 & 53.160 & 53.260 & 53.440 & 63.664 & 69.678 \\
\hline & Probability & 0.00 & 0.00 & 0.00 & 0.00 & 0.00 & 0.00 & 0.00 & 0.00 & 0.00 & 0.00 & 0.00 & 0.00 \\
\hline
\end{tabular}

Results of the Breusch-Godfrey (BG) Lagrange multiplier test to test for the existence of the high-order ARMA errors are reported in Table 2.3 of this study. The null hypothesis of this test is that there is no serial autocorrelation in the residuals up to a specified order. The maximum lag length we used for this test is 12 lags. We report two statistics: the F-statistic and the number of observations times the R-square statistic. The distribution of the former is unknown, whereas the latter is asymptotically distributed as the $x^{2}$ variable. As presented results show the null hypothesis is rejected at 1\% level for the TSX Venture, the TSX Composite capped, and the TSX Completion Index and at 5\% level for the TSX Composite, TSX 60, and the TSX Small Cap Index. The null fails to be rejected for the TSX 60 Capped Index even at 10\% level, implying that only these returns are not predictable, which support the results obtained by the autocorrelation analysis above. Overall, BG results provide evidence of a statistically significant serial autocorrelation in the residuals.

Table 2.3: Breusch-Godfrey (BG) Serial Auto-Correlation Test

This table presents the results of the BG Test. The null hyporhesis is that all autoregressive coefficients are simultaneously equal to zero. The test statistic is asymptotically chi-square distributed.

\begin{tabular}{lccccc}
\hline \multicolumn{1}{c}{ Index } & Observations & F-statistic & Probability** & Obs*R-squared & Probability*** \\
\hline SPTSX INDEX & 7089 & 2.0790 & 0.0152 & 24.90994 & 0.0153 \\
SPTSX60 INDEX & 6565 & 2.1291 & 0.0125 & 25.50458 & 0.0126 \\
SPTSX60C INDEX & 1830 & 0.7399 & 0.7130 & 8.904062 & 0.7111 \\
SPTSXS INDEX & 2211 & 1.8732 & 0.0331 & 22.39296 & 0.0333 \\
SPTSXVEN INDEX & 1566 & 2.9308 & 0.0005 & 34.70501 & 0.0005 \\
SPTSXC INDEX & 4570 & 2.4844 & 0.0030 & 29.70976 & 0.0031 \\
SPTSXM INDEX & 2211 & 2.4383 & 0.0038 & 29.05988 & 0.0039 \\
\hline
\end{tabular}

Notes: ** denotes 12 degrees of freedom. *** Based on Chi-Square approximation

\footnotetext{
${ }^{7}$ For the TSX 60 Capped Index, the reported Q-statistics at all lags except the first one fail to reject the null hypothesis at even $10 \%$ significance level.
} 
The runs test imposes no prior distributional assumptions and may be better suited to detect statistical dependencies and/or randomness than parametric tests (e.g., auto-correlation tests). The null hypothesis is that the observed series are random. Assuming that successive outcomes are independent, the number of runs is distributed normally with the following mean and standard deviation: mean $=\frac{2 n_{A} n_{B}}{n}+1$, st. dev. $=\sqrt{\frac{2 n_{A} n_{B}\left(2 n_{A} n_{B}-n\right)}{n^{2}(n-1)}}$; $n=n_{A}+n_{B}$, where $n_{\mathrm{A}}$ and $n_{\mathrm{B}}$ are the number of "+" and "-" symbols respectively. This means that the null hypothesis of randomness is rejected if the calculated number of runs falls outside of the $95 \%$ confidence interval $[\mu-1.96 \sigma \leq k \leq \mu+1.96 \sigma]$ and fails to be rejected otherwise.

Results of the runs test are presented in Table 2.4. We compute the actual number of runs and confidence interval limits using the actual return series for each index. Under the null hypothesis of a RW in return series, we expect the hypothesized number of runs to be equal to or close to the actual total number of runs. Table 2.4 results show that the null hypothesis of randomness is rejected for all index return series except for the TSX 60 Capped Index. For the TSX 60 Capped Index, we fail to reject the null hypothesis since the calculated number of runs (946) falls within the confidence interval $(874.86,958.51)$, suggesting weak-form efficiency when using that index. However, since results for the majority of indices reject the null, we can safely conclude that the results of the runs test support the results computed on the basis of other tests and suggest weak-form inefficiency in the Canadian market. Our runs test results are consistent with those of Worthington and Higgs (2003). The latter authors find that the actual number of runs falls short of the expected number of runs for all studies developed markets except those in Germany, Denmark, and Switzerland. Worthington and Higgs' (2006) run test results, in an application to the daily Australian return series, their results are consistent with ours; in an application to the monthly Australian return series, their results are inconsistent with ours.

Table 2.4: The Runs Test

The null hypothesis for this test is that the observed series are random. The null is rejected if the calculated number of runs falls outside the $95 \%$ confidence interval $[m-1.96 \mathrm{~s} £ \mathrm{k} £ \mathrm{~m}-1.96 \mathrm{~s}]$ and fails to be rejected otherwise.

\begin{tabular}{lcccc}
\hline \multicolumn{1}{c}{ Index } & \multicolumn{2}{c}{ Confidence Interval } & Estimated Number of Runs & Decision \\
\hline SPTSX INDEX & 3448.8293 & 3613.0484 & 3043.00 & reject \\
SPTSX60 INDEX & 3190.5505 & 3348.7367 & 2991.00 & reject \\
SPTSX60C INDEX & 874.8572 & 958.5146 & 946.00 & fails to be rejected \\
SPTSXS INDEX & 1057.8759 & 1149.4922 & 984.00 & reject \\
SPTSXVEN INDEX & 737.5942 & 813.9517 & 656.00 & reject \\
SPTSXC INDEX & 2212.2038 & 2344.0446 & 2020.00 & reject \\
SPTSXM INDEX & 1060.5363 & 1152.3833 & 1046.00 & reject \\
\hline
\end{tabular}

The results of univariate unit root (i.e., the Augmented Dickey-Fuller (ADF) test, the Phillips-Perron (PP) test, and the Kwiatkowski, Phillips, Schmidt, and Shin (KPSS)) tests are presented in Table 2.5 of this study. The null hypothesis for ADF and PP tests is the presence of a unit root, whereas for the KPSS test - is level stationarity. We include (exclude) the drift (trend) term into ADF and PP tests and select an appropriate lag length by minimizing the Schwartz information criterion (SIC). The PP test is a generalization of the non-augmented Dickey-Fuller (DF) procedure. The distribution theory that supports DF tests assumes that in the DF model errors are statistically independent and have a constant variance (homogeneous). The PP test relaxes this assumption, and allows disturbances to be weakly dependent and heterogeneously distributed. Enders (1995) notes that the critical values for PP and DF statistics are the same because PP statistics are modified DF t-statistics that take into account a less restrictive nature of the error process. The KPSS test uses a similar autocorrelation correction as the PP but assumes that observed time series are decomposed into the sum of a deterministic trend, a random walk with a zero variance, and a stationary error term. The KPSS test's null hypothesis is either trend- or level-stationary. Worthington and Higgs (2003) note that the advantage of the KPSS test is its ability to distinguish between the unit root and the near unit root behaviour. LR asymptotic critical values for KPSS statistics are reported in Kwiatkowski et al. (1992). 
Table 2.5: Unit Root Tests Applied to Daily Market Returns

This table reports the univariate unit root tests results using ADF, PP, and KPSS test statistics. The ADF and PP test hypothesis are $\mathrm{H}_{0}$ : unit root, $\mathrm{H}_{1}$ : no unit root (stationary). The KPSS test hypothesis is that $\mathrm{H}_{0}$ : no unit root, $\mathrm{H}_{1}$ : unit root

\begin{tabular}{|l|c|c|c|}
\hline \multirow{4}{*}{ Index } & Test & Test stat & Probability \\
\hline \multirow{3}{*}{ SPTSX INDEX } & ADF & -73.536 & $0.000^{* * *}$ \\
\cline { 2 - 4 } & PP & -73.498 & $0.000^{* * *}$ \\
\cline { 2 - 4 } & KPSS & 0.033 & Stationary \\
\cline { 2 - 4 } & ADF & -74.475 & $0.000^{* * *}$ \\
\cline { 2 - 4 } & PP & -74.325 & $0.000^{* * *}$ \\
\hline \multirow{3}{*}{ SPTSX60C INDEX } & KPSS & 0.036 & $0.000^{* * *}$ \\
\cline { 2 - 4 } & ADF & -44.951 & $0.000^{* * *}$ \\
\cline { 2 - 4 } & PP & -45.029 & Stationary \\
\hline \multirow{3}{*}{ SPTSXS INDEX } & KPSS & 0.241 & $0.000^{* * *}$ \\
\cline { 2 - 4 } & ADF & -39.810 & $0.000^{* * *}$ \\
\cline { 2 - 4 } & PP & -39.660 & $0.000^{* * *}$ \\
\hline \multirow{3}{*}{ SPTSXC INDEX } & KPSS & 0.073 & $0.000^{* * *}$ \\
\cline { 2 - 4 } & ADF & -32.883 & Stationary \\
\cline { 2 - 4 } & PP & -33.464 & $0.000^{* * *}$ \\
\hline \multirow{3}{*}{ SPTSXM INDEX } & KPSS & 0.136 & $0.000^{* * *}$ \\
\cline { 2 - 4 } & ADF & -61.576 & Stationary \\
\cline { 2 - 4 } & PP & -61.542 & $0.000^{* * *}$ \\
\hline
\end{tabular}

Notes: *** represent $1 \%$ level of significance. $* *$ represent $5 \%$ level of significance. * represent $10 \%$ level of Significance

Both, ADF and PP, test results reject the null hypothesis of a unit root at $1 \%$ significance level for all seven indices we use, indicating that the return series for the Canadian stock indices are stationary and the Canadian equity market is inefficient in the weak-form (a finding consistent with Worthinton and Higgs (2003) in relation to European equity markets). The KPSS results show that the null hypothesis of level stationarity in index return series fails to be rejected for all indices, at the $10 \%$ level of significance. Our unit root results are (in)consistent with unit root results of (Chan et al., 1997) Blasco et al. (1997), who find that the RWM (holds) does not hold on the Spanish equity market. Our unit root results also contradict unit root results of Chan et al. (1997) in relation to equity markets of Denmark, Finland, France, Netherlands, Norway, Spain, and Switzerland. Freund et al. (1997) also find that the RWM does not hold using selected individual returns of TSX-listed firms.

The consistency of the linear test results provided through non-parametric and univariate unit root tests presented above give us some confidence that the Canadian market is weak-form inefficient. Because commonly applied tests may fail to detect deterministic processes of a nonlinear nature that generate variates appearing random (Pandey et al., 1998), we apply further tests better suited to capture the nonlinear dynamics, which were developed with advances in the theory of chaos: the $\mathrm{BDS}^{8}$ test and the R/S analysis.

The BDS tests if data series are independently and identically distributed (IID). The usual procedure is to apply the test to the pre-whited data for which the existence of a unit root is ruled out (Pandey et al., 1998). If the test rejects the null of an IID, it suggests a possibility for some form of non-linear dynamics. Pandey et al. (1998), however, note that the rejection of the null does not provide convincing evidence for the presence of nonlinear dynamics because structural shifts in the data series can contribute to the rejection of the null. For robustness, we run the BDS test on the filtered data over the full sample period (7105 observations) and for a sample of 1506 end-ofday observations. The process of filtering data series is the process of a removal of a linear structure present in the series. The test is applied to filtered residuals from the second order autoregression model, which is sufficient to remove the linear structure present in all return series.

\footnotetext{
${ }^{8}$ For samples with over 500 observations, the BDS statistic has a limiting normal distribution under the null of an independently and identically distribution (IID).
} 
The results presented in Tables 2.6a and 2.6b report BDS statistics for each return residual series that are calculated using $\in$ values of $0.5 \sigma$ and $1 \sigma^{9}$. We use $12(\mathrm{~m}=2, \ldots, 12)$ correlation dimensions, which roughly represent the number of non-linear factors that describe the data, for all seven indices studied.

Except for the TSX 60 Capped Index, ${ }^{10}$ Tables 2.6a and 2.6b report statistically significant (at $1 \%$ level) values for BDS statistics calculated for all seven indices using extended individual samples for each index and a common sample across all indices encompassing 1506 end-of-day observations. Results show that the null of an IID is rejected on the basis of not only extended individual samples for each index but also a common sample across all indices, implying that the returns series for all indices are not random. The rejection of the IID using the BDS statistic implies that the data follows either the deterministic chaos process or a stochastic, completely, unpredictable, process. Overall, the BDS test results provide evidence of a deterministic chaotic process (non-linear dependence) underlying the residuals after fitting the $\operatorname{AR}(2)$ model to remove the linear structure. These results are consistent with those of Blasco et al. (1997) and Pandey et al. (1998). Blasco et al. (1997) strongly reject the null hypothesis of an IID governing the Spanish equity returns. Pandey et al. (1998), using the BDS test, reject the null for index returns of Germany, France, Italy, and the US.

Table 2.6a: BDS Statistics for Returns of Canadian Stock Market Indices

This table presents the results of the BDS test for the full sample period (7105 observations) using standard deviation to specify $\varepsilon$ (distance measure). The null hypothesis is that the return series are Independently and Identically Distributed (IID). All the BDS statistics are compared to critical values shown at the bottom of this table.

\begin{tabular}{|c|c|c|c|c|c|c|c|c|}
\hline \multicolumn{9}{|c|}{ Stock Market Index } \\
\hline m: & $\varepsilon / \sigma$ & $\begin{array}{l}\text { SPTSX } \\
\text { INDEX }\end{array}$ & $\begin{array}{c}\text { SPTSX60 } \\
\text { INDEX }\end{array}$ & $\begin{array}{l}\text { SPTSX60 } \\
\text { C INDEX }\end{array}$ & $\begin{array}{l}\text { SPTSXS } \\
\text { INDEX }\end{array}$ & $\begin{array}{c}\text { SPTSXVEN } \\
\text { INDEX }\end{array}$ & $\begin{array}{c}\text { SPTSXC } \\
\text { INDEX }\end{array}$ & $\begin{array}{c}\text { SPTSXM } \\
\text { INDEX }\end{array}$ \\
\hline 2 & 0.5 & 17.8627 & 15.7255 & $3.3286^{*}$ & 6.8984 & 5.5714 & 12.2160 & 9.2924 \\
\hline 3 & 0.5 & 23.7578 & 20.8666 & 6.0694 & 9.1673 & 7.3237 & 17.1564 & 13.9107 \\
\hline 4 & 0.5 & 28.2386 & 24.7305 & 8.1129 & 11.5212 & 8.8284 & 20.9490 & 16.4765 \\
\hline 5 & 0.5 & 33.6244 & 29.0302 & 9.7966 & 13.3749 & 10.3198 & 25.1551 & 19.4497 \\
\hline 6 & 0.5 & 39.9180 & 34.0791 & 12.2109 & 15.1608 & 12.4018 & 30.5711 & 22.2937 \\
\hline 7 & 0.5 & 47.6100 & 39.7524 & 15.1353 & 17.8214 & 14.4439 & 36.8163 & 25.8007 \\
\hline 8 & 0.5 & 56.9893 & 46.7826 & 19.9038 & 21.1479 & 17.5716 & 44.7440 & 30.7317 \\
\hline 9 & 0.5 & 69.0059 & 55.1839 & 24.2621 & 23.5395 & 22.2367 & 55.3953 & 36.6894 \\
\hline 10 & 0.5 & 84.0344 & 65.0546 & 27.6325 & 25.4438 & 25.0577 & 67.6994 & 41.9114 \\
\hline 11 & 0.5 & 103.9137 & 78.2382 & 29.5644 & 25.1011 & 26.6623 & 79.3727 & 50.6285 \\
\hline 12 & 0.5 & 132.4079 & 95.4300 & 32.0302 & 24.4018 & 33.0358 & 101.7289 & 63.7833 \\
\hline 2 & 1 & 19.2584 & 16.7739 & 3.8891 & 8.4905 & 7.0497 & 12.2085 & 10.2573 \\
\hline 3 & 1 & 24.8833 & 21.9684 & 6.7693 & 11.1913 & 9.3836 & 17.0364 & 14.6445 \\
\hline 4 & 1 & 28.6917 & 25.6425 & 8.6268 & 13.5314 & 11.3225 & 20.4526 & 16.9701 \\
\hline 5 & 1 & 32.7233 & 29.2621 & 10.3212 & 15.1557 & 12.8792 & 23.9582 & 19.2425 \\
\hline 6 & 1 & 36.8261 & 32.8973 & 12.1897 & 16.4817 & 14.3255 & 27.5331 & 21.2449 \\
\hline 7 & 1 & 41.3483 & 36.6614 & 14.0521 & 17.9876 & 15.8929 & 31.3633 & 23.5045 \\
\hline 8 & 1 & 46.5854 & 41.1398 & 16.3579 & 19.8853 & 17.4900 & 35.8736 & 26.4438 \\
\hline 9 & 1 & 52.5656 & 46.2018 & 18.5169 & 21.8529 & 19.3437 & 41.0046 & 29.5906 \\
\hline 10 & 1 & 59.5761 & 52.0039 & 21.4872 & 24.0308 & 21.3923 & 47.2538 & 33.1616 \\
\hline 11 & 1 & 68.3071 & 59.2167 & 25.1199 & 26.7114 & 23.7759 & 54.9305 & 37.6955 \\
\hline 12 & 1 & 78.8348 & 67.9458 & 29.4199 & 29.7767 & 26.7506 & 64.5768 & 43.2830 \\
\hline
\end{tabular}

Notes: $\mathrm{m}=$ embedding dimension. $\mathrm{n}=7105$ observations. Except where denoted by *all BDS statistics are significant at $1 \%$ level. See the following table generated by Brock et al. (1987) for specifics:

With 250 observations

\begin{tabular}{ccccc} 
& \multicolumn{2}{c}{ Significance Level: $\mathbf{5 \%}$} & \multicolumn{2}{c}{ Significance Level: $\mathbf{1 \%}$} \\
\cline { 2 - 5 } $\mathrm{m}:$ & $\varepsilon / \sigma=0.50$ & $\varepsilon / \sigma=1.00$ & $\varepsilon / \sigma=0.50$ & $\varepsilon / \sigma=1.00$ \\
\cline { 2 - 5 } 2 & 2.35 & 1.86 & 3.71 & 2.79 \\
3 & 2.59 & 1.91 & 4.04 & 2.92 \\
4 & 3.02 & 1.98 & 4.85 & 2.96 \\
5 & 3.88 & 2.10 & 6.44 & 3.06 \\
\hline
\end{tabular}

\footnotetext{
${ }^{9}$ According to the BDS test, a lower $\in$ value represent a more stringent criteria since points in the m-dimensional space must be clustered together to qualify as being "close." Hence, $\epsilon=0.5 \sigma$ reflects the most stringent test, while $\epsilon=1.00 \sigma$ is a most relaxed test (Pandey et al., 1998). ${ }^{10}$ The BDS statistic (at $\mathrm{m}=2$ ) for the TSX 60 capped index and for the extended sample is significant at $5 \%$ level.
} 
Table 2.6b: BDS Statistics for Returns of Canadian Stock Market Indices

This table presents the results of the BDS test for 1506 observations using standard deviation to specify $\varepsilon$ (distance measure). The null hypothesis is that the return series are Independently and Identically Distributed (IID). All the BDS statistics are compared to criticall values shown at the bottom of this table.

\begin{tabular}{ccccccccc}
\hline \multicolumn{1}{c}{ Stock Market Index } \\
\hline $\mathbf{m :}$ & $\boldsymbol{\varepsilon} / \boldsymbol{\sigma}$ & $\begin{array}{c}\text { SPTSX } \\
\text { INDEX }\end{array}$ & $\begin{array}{c}\text { SPTSX60 } \\
\text { INDEX }\end{array}$ & $\begin{array}{c}\text { SPTSX60C } \\
\text { INDEX }\end{array}$ & $\begin{array}{c}\text { SPTSXS } \\
\text { INDEX }\end{array}$ & $\begin{array}{c}\text { SPTSXVEN } \\
\text { INDEX }\end{array}$ & $\begin{array}{c}\text { SPTSXC } \\
\text { INDEX }\end{array}$ & $\begin{array}{c}\text { SPTSXM } \\
\text { INDEX }\end{array}$ \\
\hline 2 & 0.5 & 3.9337 & 3.7441 & 3.7408 & 5.7478 & 5.7123 & 3.9225 & 4.3674 \\
3 & 0.5 & 5.6810 & 5.3787 & 5.3680 & 7.7126 & 7.2414 & 5.6705 & 6.3140 \\
4 & 0.5 & 6.9628 & 6.7307 & 6.7414 & 9.1422 & 8.7135 & 6.9563 & 7.4311 \\
5 & 0.5 & 8.3499 & 8.1224 & 8.0548 & 10.3240 & 10.2199 & 8.3420 & 8.3750 \\
6 & 0.5 & 10.0550 & 10.1500 & 10.0380 & 11.0112 & 12.3146 & 10.0593 & 8.7025 \\
7 & 0.5 & 12.2115 & 12.4291 & 12.2500 & 12.7189 & 14.2531 & 12.2161 & 9.2226 \\
8 & 0.5 & 17.1029 & 15.6382 & 15.6107 & 14.7715 & 17.5424 & 17.1086 & 8.9010 \\
9 & 0.5 & 20.6498 & 18.9245 & 18.8907 & 15.3146 & 22.5561 & 20.6567 & 6.2292 \\
10 & 0.5 & 25.0824 & 20.1114 & 20.0743 & 17.7536 & 27.0726 & 25.0910 & 4.6948 \\
11 & 0.5 & 26.7169 & 21.7151 & 21.6739 & 21.2899 & 31.8521 & 26.7266 & 6.5744 \\
12 & 0.5 & 34.6084 & 24.4439 & 24.3960 & 27.4985 & 40.4555 & 34.6214 & 6.4082 \\
\hline 2 & 1 & 4.3080 & 4.2856 & 4.2493 & 6.8692 & 7.0230 & 4.3086 & 5.2869 \\
3 & 1 & 6.2267 & 6.1309 & 6.1033 & 9.0718 & 9.2304 & 6.2289 & 7.3292 \\
4 & 1 & 7.4397 & 7.4517 & 7.4406 & 10.5191 & 11.1364 & 7.4419 & 8.4469 \\
5 & 1 & 8.6790 & 8.7529 & 8.7588 & 11.6293 & 12.5732 & 8.6834 & 9.4791 \\
6 & 1 & 9.9018 & 10.3120 & 10.3288 & 12.1821 & 13.9753 & 9.9063 & 10.0226 \\
7 & 1 & 11.2051 & 11.7860 & 11.8060 & 12.9479 & 15.4669 & 11.2079 & 10.7658 \\
8 & 1 & 12.7865 & 13.5132 & 13.5437 & 13.9850 & 16.9762 & 12.7892 & 11.9367 \\
9 & 1 & 14.0229 & 15.0287 & 15.0610 & 14.8381 & 18.7058 & 14.0235 & 12.9665 \\
10 & 1 & 15.7652 & 17.0622 & 17.1154 & 15.9814 & 20.6424 & 15.7636 & 14.1118 \\
11 & 1 & 18.0576 & 19.7325 & 19.8131 & 17.5631 & 23.0050 & 18.0584 & 15.6029 \\
12 & 1 & 20.7175 & 22.8028 & 22.9030 & 19.5003 & 25.9544 & 20.7184 & 17.5474 \\
\hline
\end{tabular}

Notes: $\mathrm{m}=$ embedding dimension. $\mathrm{n}=1506$ observations. All BDS statistics are significant at $1 \%$ level. See the following table generated by Brock et al (1987) for specifics:

With 250 observations

Significance Level: $5 \%$

Significance Level: $1 \%$

\begin{tabular}{ccccc}
\cline { 2 - 5 } $\mathrm{m}:$ & $\varepsilon / \sigma=0.50$ & $\varepsilon / \sigma=1.00$ & $\varepsilon / \sigma=0.50$ & $\varepsilon / \sigma=1.00$ \\
\cline { 2 - 5 } 2 & 2.35 & 1.86 & 3.71 & 2.79 \\
3 & 2.59 & 1.91 & 4.04 & 2.92 \\
4 & 3.02 & 1.98 & 4.85 & 2.96 \\
5 & 3.88 & 2.10 & 6.44 & 3.06 \\
\hline
\end{tabular}

To further test for the possibility of a chaotic random data generating process governing Canadian stock returns, we use the modified Lo's Rescaled Range (R/S) statistic. ${ }^{11}$ The original R/S accounts for zero autocorrelations in the variance estimator and is defined as the range of the partial sums of deviations of return series from the mean, scaled by its standard deviation. Lo's (1991) modification of the original R/S statistic allows accounting for autocovariances up to lag $\mathrm{n}$ within the variance estimator. Hurst exponent is estimated through OLS of the form: $\log (\mathrm{R} / \mathrm{S})=\mathrm{H} \times \log (\mathrm{N})+\log (a)$ with $a$ denoting a constant and $\mathrm{H}-$ the Hurst exponent. An $\mathrm{H}$ of 0.5 implies a non-deterministic process, that is, a process for which past history of events has no impact on the future. An $\mathrm{H}$ of less than 0.5 implies an anti-persistent behaviour, meaning that a positive trend in one N-length sub-period is more likely to be followed by a negative trend in the next $\mathrm{N}$-length sub-period. An $\mathrm{H}$ of greater than 0.5 implies a persistent behaviour, meaning that a positive trend is more likely to be followed by another positive trend.

${ }^{11}$ Lo's (1991) R/S is given by the following formula: $\hat{Q}^{q}{ }_{n}=\frac{1}{\sigma_{n}(q)}\left[\max \sum_{j=1}^{n}\left(X_{j}-\bar{X}_{n}\right)-\min \sum_{j=1}^{n}\left(X_{j}-\bar{X}_{n}\right)\right]$ where
$\hat{\sigma}_{n}{ }_{n}(q)=\frac{1}{n} \sum_{j=1}^{n}\left(X_{j}-\bar{X}_{n}\right)^{2}+\frac{2}{n} \sum_{j=1}^{q} \varpi_{j}(q)\left[\sum_{i=j+1}^{n}\left(X_{i}-\bar{X}_{n}\right)\left(X_{i-j}-\bar{X}_{n}\right)\right]$
and
$\varpi_{j}(q)=1-\frac{j}{q+1}, q<n$. 
We summarise the results of $\mathrm{R} / \mathrm{S}$ analysis in Table 2.7 .

Table 2.7: Hurst Exponents Estimates for Daily Return Series

\begin{tabular}{|c|c|}
\hline Index & Hurst Exponent \\
\hline SPTSX INDEX & 0.446656 \\
\hline SPTSX60 INDEX & 0.512007 \\
\hline SPTSX60C INDEX & 0.634228 \\
\hline SPTSXS INDEX & 0.386071 \\
\hline SPTSXVEN INDEX & 0.412365 \\
\hline SPTSXC INDEX & 0.454716 \\
\hline SPTSXM INDEX & 0.452448 \\
\hline
\end{tabular}

The calculated Hurst exponents generally confirm the presence of a non-linear dependencies present in Canadian return series. They suggest that all seven index returns are characterized by an anti-persistent behaviour for which return series move in trend-reversing patterns. Specifically, the return series for the TSX Composite $(\mathrm{H}=$ $0.45)$, the TSX $60(H=0.51)$, the TSX 60 Capped $(H=0.63)$, the TSX Composite Capped $(H=0.45)$, and the TSX Completion $(\mathrm{H}=0.45)$ indices all exhibit weaker anti-persistent behaviour, whereas the return series for the TSX Small Cap index $(H=0.39)$ and the TSX Venture index $(H=0.41)$ exhibit stronger temporal anti-persistent dependencies. Thus, most of Canadian stock index return series are anti-persistent, with a higher likelihood for an upward (downward) trend in one cycle to be followed by a declining (increasing) trend in the next cycle. Pandey et al. (1998) also use the R/S analysis and find similar results for the German, French, Italian, and US stock market. They conclude that some form of a temporal dependency exists in those four equity examined indices. Freund et al. (1997) R/S results are in contrast to ours but they use monthly TSX index returns: returns do not radically depart from the RWM (except for relatively long time horizons of over 60 months).

Therefore, the results of all tests used in this study, together with results of tests for non-linear dependence, are consistent and provide evidence that the Canadian stock market is inefficient.

\section{CONCLUSION}

This study examines the validity of the weak-form EMH on Canadian equity markets, using a variety of TSX indices. We conduct an empirical analysis using continuously compounded Canadian equity returns using seven Canadian stock market indices (the TSX Composite Index; the TSX 60 Index, the TSX 60 Capped Index, the TSX Small Cap Index, the TSX Venture Index, the TSX Composite Capped Index, and the TSX Completion Index). We employ different statistical techniques to assess the weak-form market efficiency. Overall, the results of the empirical analysis suggest that the Canadian stock market returns are predictable, hence violating the notion of market efficiency. The latter conclusion is invariant to the choice of a statistical technique used.

We use parametric and non-parametric test procedures to test the validity of the EMH on the TSX. Parametric tests include autocorrelation and BG tests. Non-parametric tests include the BDS and the runs tests. Reported Q-statistics reject the null hypothesis of no autocorrelation for all index returns, except for the TXS 60 Capped Index. The Box-Pierce test results are consistent with the BG test and the runs test results. The latter tests also fail to reject the null hypothesis of a zero autocorrelation for Canadian equity index returns with the exception of the TSX 60 capped index return.

Univariate unit root tests (ADF, PP, and KPSS) are used to test for stationarity in return series of seven indices. The null for the ADF and the PP tests is the presence of a unit root, whereas the null for the KPSS test is level stationarity. The ADF and the PP tests reject the null of a unit root, whereas the KPSS tests fail to reject the null of level stationarity for all index returns.

After ruling out the first order integration of return series, we proceed to test for the presence of non-linear dynamics (to detect deterministic processes of a nonlinear nature which linear tests may fail to capture). For this reason, we use the BDS test and the R/S analysis. The BDS test results uniformly suggest the rejection of a null of an IID governing residuals from the AR(2) model fitted to equity returns. For robustness, we run the BDS test using 
individual samples across all seven indices and a common sample encompassing 1506 end-of-day observations. The conclusion remains invariant to the choice of the sample period and suggests that all Canadian equity returns exhibit non-randomness in their movements. We also use the modified Lo's R/S statistic to test for the presence of a chaotic random data generating process which might lead to the rejection of an IID hypothesis. Results show that Canadian equity returns exhibit long-memory properties (i.e., are marginally anti-persistent).

Results of this study contradict our expectation of an efficient TSX equity market and suggest that Canadian index equity returns possess properties of a deterministic non-linear weakly trend-reversing process. Further research might focus on examining how the predictability exhibited by the TSX equity returns can be used to generate abnormal returns, net of management fees and commissions, to investors, traders, and market makers.

\section{AUTHOR INFORMATION}

Ilona Shiller is an Associate Professor at the University of New Brunswick. She received her PhD degree from the University of Manitoba. Her research interests are in financial markets, fixed-income securities, and investments. E-mail: ishiller@unb.ca (Corresponding author)

Ishmael Radikoko is a finance lecturer at the University of Botswana. He holds an MBA degree from the University of New Brunswick and is interested in investments (equity and fixed-income markets). E-mail: ishmaelradikoko@yahoo.com

\section{REFERENCES}

1. Aitken, M., \& Siow, A. (2003). Ranking equity markets on the basis of market efficiency and integrity (pp. xliv-lv). Hewlett-Packard Handbook of World Stock, Derivative and Commodity Exchanges.

2. Blasco, N. (1997). The random walk hypothesis in the Spanish stock market. Journal of Business Finance and Accounting, 24(5), 0306-686X.

3. Chan, K. C., Gup, B. E., \& Pan, M. S. (1997). International stock market efficiency and intergration: A study of eighteen nations. Journal of Business Finance and Accounting, 24(6), 0306-686X.

4. $\quad$ Enders, W. (1995). Applied econometric time series. US: John Wiley and Sons, Inc.

5. Freund, W. C., \& Pagano, M. S. (2000). Market efficiency in specialist markets before and after automation. The Financial Review, 35, 79-104.

6. Freund, W. C., Larrain, M., \& Pagano, M. S. (1997). Market efficiency before and after the introduction of electronic trading at the Toronto stock exchange. Review of Financial Economics, 6(1), 29-56.

7. Kwiatkowski, D., Phillips, P. C. B., Schmidt, P., \& Shin, Y. (1992). Testing the null hypothesis of stationarity against the alternative of a unit root. Journal of Econometrics, 54, 159-178.

8. Pandey, V., Kohers, T., \& Kohers, G. (1998). Deterministic nonlinearity in the stock returns of major European equity markets and the United States. Financial Review, 33, 45-64.

9. Porteba, M. J., \& Summers, L. H. (1988). Mean reversion in stock prices. Journal of Financial Economics, 22, 27-59.

10. Worthinton, A. C., \& Higgs, H. (2003). Weak-form market efficiency in european emerging and developed stock markets. (Discussion Paper, No. 159).

11. Worthinton, A. C., \& Higgs, H. (2006). Efficiency in the Australian stock market, 1875-2006: A note on extreme long-run random walk behaviour. (Working paper). School of Accounting and Finance, University of Wollongong. 


\section{APPENDIX 1: DESCRIPTION OF STOCK INDICES USED AND THEIR CONSTRUCTION}

S\&P/TSX indices represent the performance of the Canadian equity market and their composition is frequently revised to incorporate changes in market capitalization classifications (large vs mid vs small cap) and reflect changes resulting from additions/deletions to the index, rights issues, share buybacks and issuances, and spin-offs.

1. TSX Composite Index is the headline index and the principal broad market measure for the Canadian equity markets. It includes common stocks and income trust units. Constituents of the index are also members of either S\&P/TSX equity indices (the S\&P/TSX equity 60 (large-cap), and the S\&P/TSX equity completion (mid-cap)) or indices that include income trusts (the S\&P/TSX income trust, the S\&P/TSX capped REIT, and the S\&P/TSX Capped Energy trust), or both. To be included in the index, the security must: (i) represent a minimum float-adjusted weight of $0.05 \%$ of the total market capitalization of the index using its Quoted Market Value (QMV); (ii) have a minimum volume weighted price (VWP) of \$1; and (iii) be relatively liquid with liquidity being measured by both, the sum of trading volume, dollar value traded and number of transactions and the frequency of security trading in a year.

2. S\&P/TSX 60 is a subset of the S\&P/TSX Composite and tracks the Canadian stock market using 60 large cap, liquid (with a reasonable turnover) Canadian companies listed on the TSX. The Index Committee includes securities into this index that are large (in terms of float QMV), liquid (with float turnover of at least 0.35), reflective of the GICS sector weights in the S\&P/TSX Composite Index.

3. S\&P/TSX Small Cap Index includes common stocks and income trust units of small cap liquid Canadian companies and is representative of the Canadian small cap equity market. It is frequently used by index mutual funds, exchange traded funds, index portfolios, and index futures and options and includes stocks of companies included in the S\&P/TSX composite index, with a market capitalization between $\$ 300$ million and $\$ 2$ billion. To be included in the index, the security must: (i) the total and float-adjusted QMV of the security, based on the volume weighted average price (VWAP) over the last three trading days of the month-end prior to the annual review, must fall within the range between $\$ 100$ million and $\$ 1.5$ billion; and (ii) be relatively liquid with liquidity being measured by both, the sum of dollar value traded, the float turnover ratio, and the frequency of security trading in a year.

4. The S\&P/TSX Venture Composite is a broad market capitalisation-based index designed to measure the performance of securities listed on the TSX Venture exchange. To be eligible for inclusion in the index, the company must be incorporated under Canadian federal, provincial, or territorial jurisdictions and its stocks listed on the TSX Venture exchange for at least 12 months. Additionally, the security must represent a minimum float-adjusted weight of $0.05 \%$ of the total market capitalization of the index using its Quoted Market Value (QMV).

5. S\&P/TSX 60 capped and S\&P/TSX composite capped indices are calculated by Standard and Poor's using capped versions of headline indices. The latter indices are capped at either 25 or $10 \%$. This means that the market value weight of a single stock is restricted to $25 \%$ (10\%) or less. The cap works by increasing or reducing the number of trust units or shares in the float until the weight attributed to a single stock equals $25 \%(10 \%)$ of the relevant index.

6. S\&P/TSX Completion (mid cap) index includes stocks of companies included in the S\&P/TSX composite index, with a market capitalization between $\$ 2$ and $\$ 10$ billion. The index consists of stocks that are excluded from the TSX 60 (large cap) and the TSX small cap index. 